\title{
Influence of temperature on the properties of fireproof materials
}

\author{
Tatiana Budykina $^{1 *}$, and Yevgenia Anosova ${ }^{2}$ \\ ${ }^{1}$ Academy of Civil Defence EMERCOM of Russia, Moscow, Russia \\ ${ }^{2}$ D. Mendeleev University of Chemical Technology of Russia, Moscow, Russia
}

\begin{abstract}
The results of experimental studies of the behavior of fireproof materials of Russian production - OGNEZA-LTU, OGNEZA-M-KOR, OG-NEZA-M-KOR (NG), «OGNEBAZALT»PMBOR, OGNEZA-GT under thermal action are presented. Research method - synchronous thermal analysis TG/DCS/dDSC, including differential scanning calorimetry (DSC) and thermogravimetry (TG). Experimental conditions on the NETZSCH thermal analyzer: measurement mode - TG/DCS/dDSC; heating rate: $20{ }^{\circ} \mathrm{C} / \mathrm{min}$; heating - up to $1000{ }^{\circ} \mathrm{C}$; atmosphere $-\mathrm{N}_{2}$. The rates of weight loss of the investigated fire-retardant materials have been studied. A high rate of weight loss was established for the OGNEZA-LTU samples $\left(20.5 \% / \mathrm{min}\right.$ at $\left.335{ }^{\circ} \mathrm{C}\right)$ and OGNEZA-GT $(11.9 \% / \mathrm{min}$ at 369 ${ }^{\circ} \mathrm{C}$ ); low - OGNEZA-M-KOR (NG) - $1.7 \% / \mathrm{min}$ at $349^{\circ} \mathrm{C}$, OGNEZA-MKOR $-6.1 \% / \mathrm{min}$ at $341{ }^{\circ} \mathrm{C}$, «OGNEBASALT» PMBOR - $3.5 \% / \mathrm{min}$ at $388{ }^{\circ} \mathrm{C}$. Time intervals of weight loss were determined: all test samples had maximum weight loss in the range of 15-20 minutes. The temperature ranges of the maximum rate of weight loss were determined: $349-388^{\circ} \mathrm{C}$. The best heat-resistant properties were shown by OGNEZA-M-KOR (NG), «OGNEBASALT» PMBOR, OGNEZA-M-KOR. It is proposed to consider the revealed properties when using fire retardant materials for the constructive fire hazard of civil and industrial facilities.
\end{abstract}

\section{Introduction}

An urgent task of our time is the production and use of fireproof materials to increase the stability of buildings and structures in the event of a fire and the accumulation of knowledge about the behavior of materials under temperature exposure. The thermal properties of fire retardant materials are important parameters for use on a specific protected object.

Research work on fire-resistant materials is mainly aimed at studying the properties of fire retardants, the mechanism of retarding combustion, pyrolysis and combustion products of materials, increasing the fire resistance of materials, assessing the flammability and fireretardant efficiency of coatings for metal structures, intumescent fire-retardant materials [112]. However, data on thermal properties, especially on the rate of weight loss of Russianmade fire-resistant materials, are scarce [13-18].

\footnotetext{
* Corresponding author: tbudykina@yandex.ru
} 
Purpose of the research: to study the effect of temperature on the properties of Russianmade fire-retardant materials.

Research objectives:

- study of the rate of weight loss of fire retardant materials;

- determination of temperature ranges for weight loss;

- determination of materials with the best heat-resistant properties.

Characteristics of the research object.

The object of the study was samples of Russian-made fire-retardant materials - Ogneza LLC, St. Petersburg, and OGNEBAZALT MSK LLC, Balashikha, Moscow region (Figure 1):

- fire-fighting tape OGNEZA-LTU and seals: OGNEZA-M-KOR and OG-NEZA-M-KOR (NG);

- fire retardant material «OGNEBASALT»PMBOR;

- fire retardant thermo-expanding sealant OGNEZA-GT in the form of mineral wool heatinsulating plate.

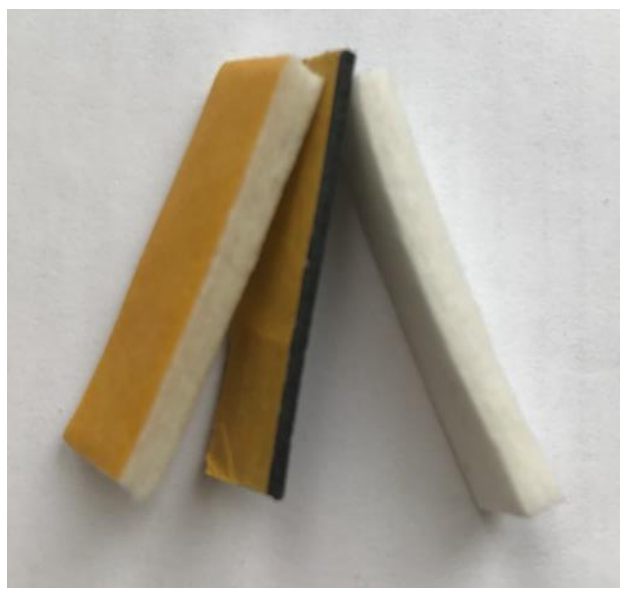

a)

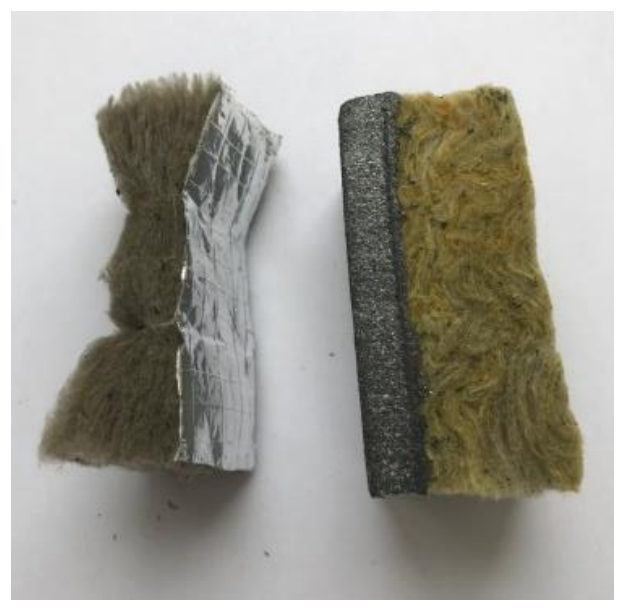

b)

$a$ is from left to right - self-adhesive sealant OGNEZA-M-KOR $3 \times 10$ (thickness, mm $\times$ width, $\mathrm{mm}$ ); heat sealing tape OGNEZA-LTU $1.5 \times 10$; seal OGNEZA-M-KOR (NG) $3 \times 10$ ); b is from left to right - «OGNEBASALT»PMBOR (thickness $-8 \mathrm{~mm}$ ); sealant OGNEZA-GT (thickness $30 \mathrm{~mm})$.

Fig. 1. Investigated samples of fire retardant materials

Thermo-sealing tape OGNEZA-LTU is designed to fill the voids, gaps between the fire door frame and the door leaf to block the penetration of smoke and fire into adjacent rooms. Fireproof seals-whether OGNEZA-M-KOR, OGNEZA-M-KOR (NG) are used to fire air ducts and equipment insulation. Fire-retardant basalt material PMBOR is used for fire protection of building structures, air ducts, thermal insulation of pipelines, equipment, residential and industrial buildings and structures, attic floors of houses. Fire retardant thermally expanding sealant OGNEZA-GT in the form of a mineral wool heat-insulating plate has found application for fire protection and thermal insulation of reinforced concrete floor slabs, for sealing construction joints, cable and ventilation passages of communications through walls and ceilings.

According to the manufacturers, the OGNEZA-LTU thermal sealing tape is made of rubber, thermally expanding graphite, flame retardant mixture, PVC adhesive tape, seals OGNEZA-M-KOR, OGNEZA-M-KOR (NG) - from silica; «OGNEBASALT»PMBOR and OGNEZA-GT - from basalt rocks. 


\section{Methods}

To study the effect of temperature on the properties of fire retardant materials, the method of synchronous thermal analysis (STA) (GOST R 55134-2012) was used, including differential scanning calorimetry (DSC) and thermogravimetry (TG). The study by the STA method was carried out at the Department of Fire Safety of the Federal State Budgetary Educational Institution of Higher Education «Academy of Civil Protection» on a thermal analyzer STA 449 F3 Jupiter of the German company «NETZSCH».

Characteristics of the experimental conditions: measurement mode - TG/ DCS/dDSC; heating rate: $20^{\circ} \mathrm{C} / \mathrm{min}$; heating - up to $1000^{\circ} \mathrm{C}$; atmosphere $-\mathrm{N}_{2}$.

\section{Results and Discussion}

Figures 2-6 show the dTG curves of the studied fire-retardant materials, reflecting the rate of decrease in the mass of the samples over time.

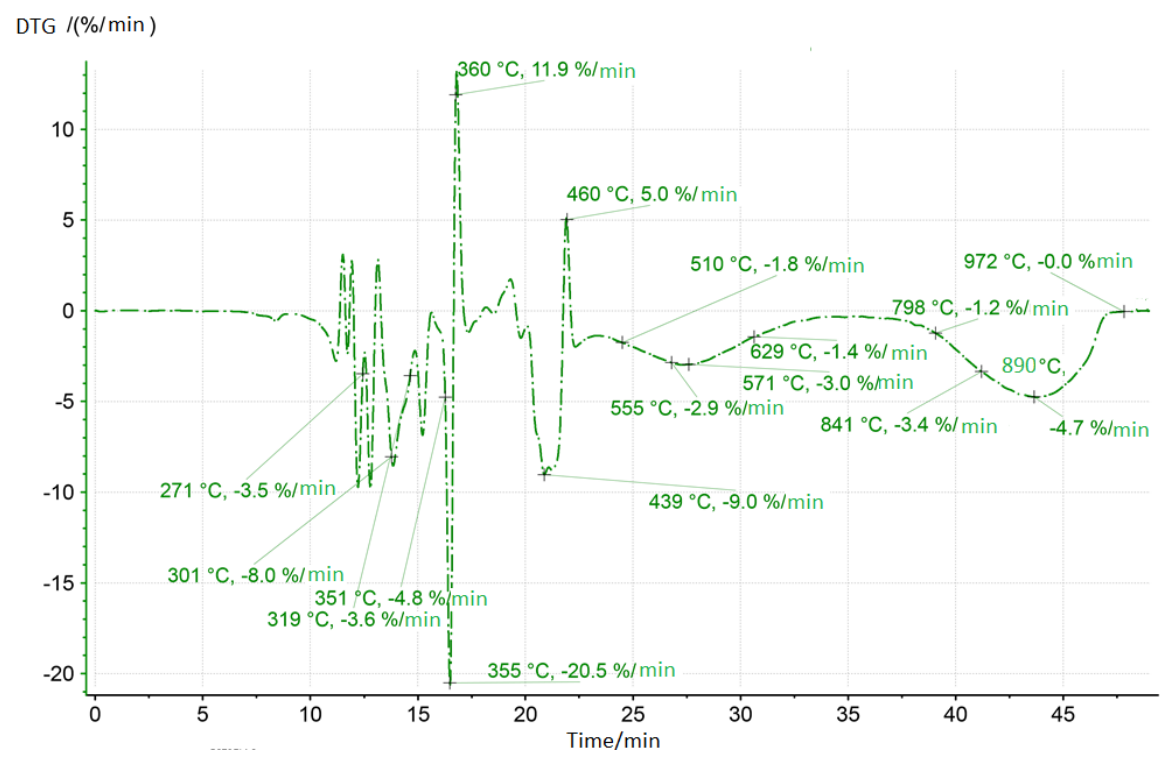

Fig. 2. The rate of change in the mass of the sample of the tape of thermosealing OGNEZA-LTU under thermal action (DTG, \%/min) 


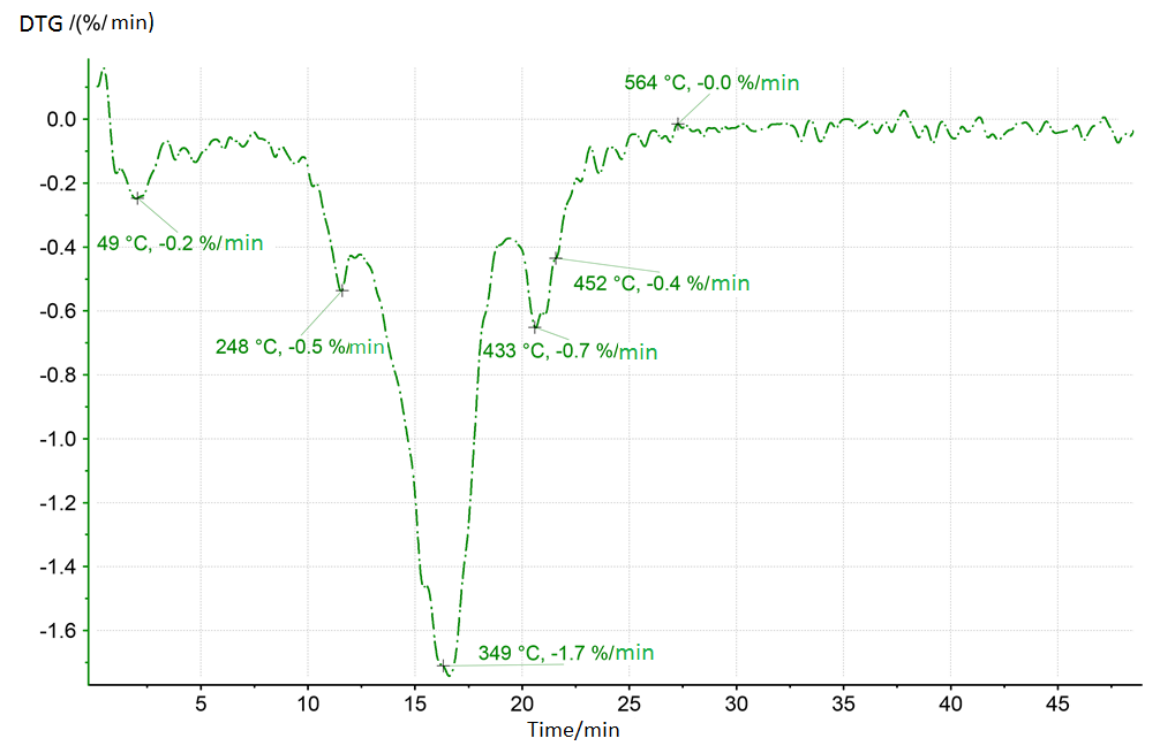

Fig. 3. The rate of change in the mass of the sample sealant OGNEZA-M-KOR (NG) with thermal exposure (DTG, \% / $\mathrm{min}$ ).

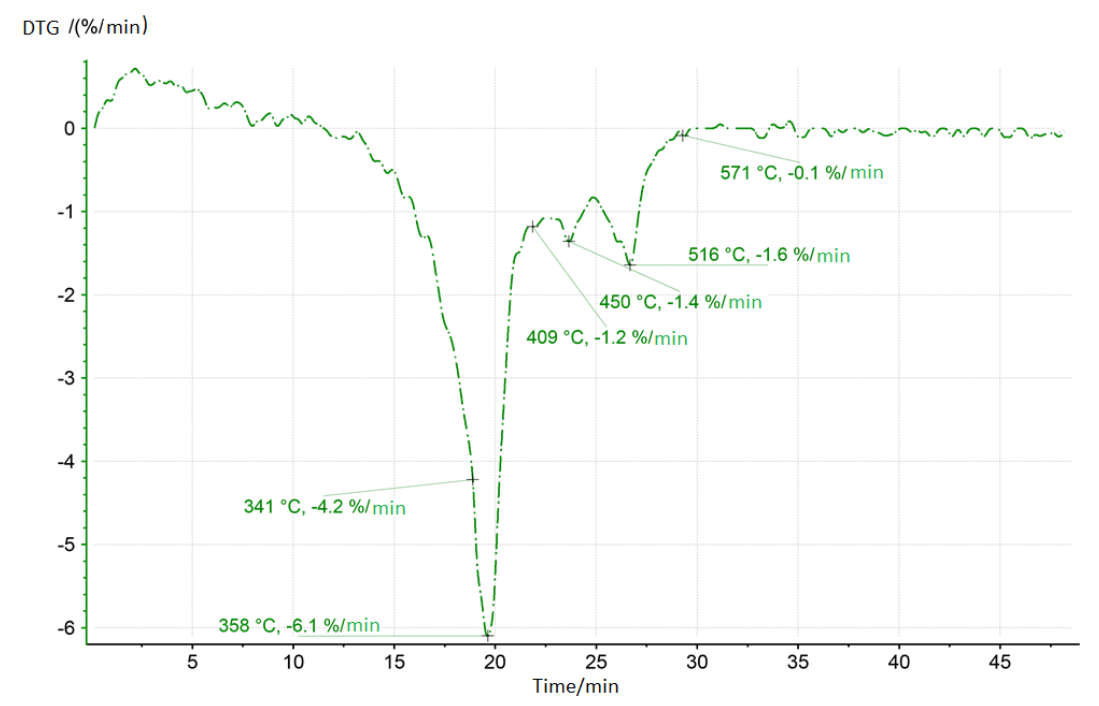

Fig. 4. The rate of change in the mass of the sample sealant OGNEZA-M-KOR with thermal exposure (DTG, \% / min) 


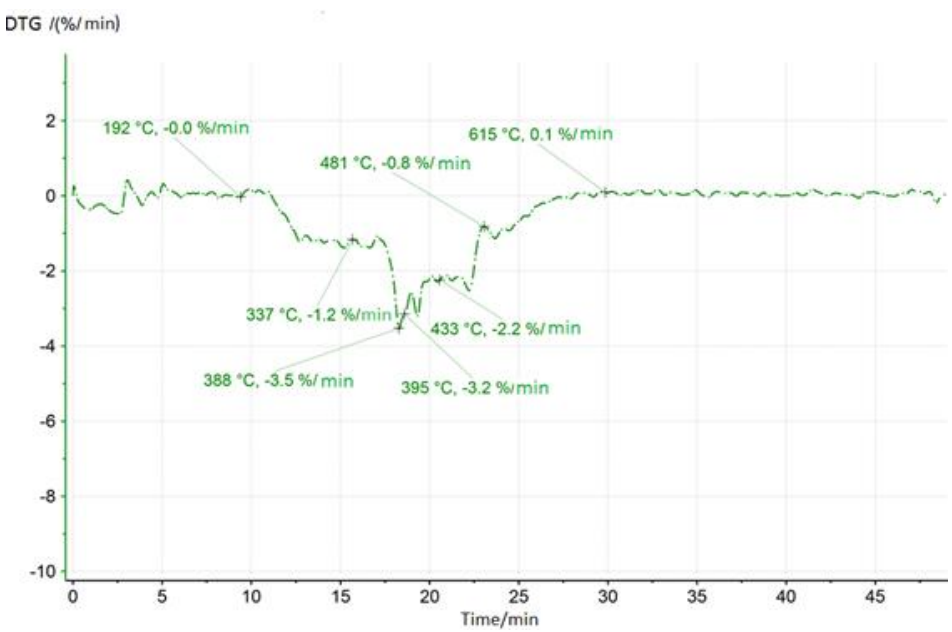

Fig. 5. The rate of change in the mass of the sample of the fire-retardant material «OGNEBASALT» PMBOR under thermal action (DTG, \% / min)

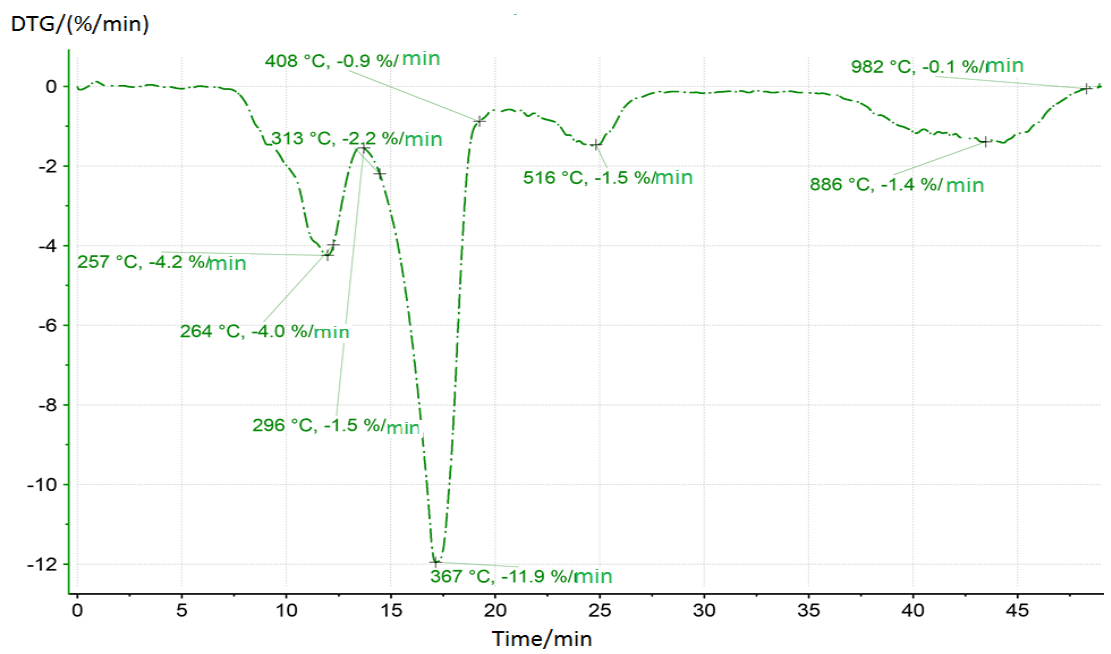

Fig. 6. The rate of change in the mass of the sample of the fire-retardant thermally expanding sealant OGNEZA-GT under thermal action (DTG, \%/min)

As can be seen from figures 2-6, the behavior of fire-retardant materials under temperature exposure differs from each other; however, the non-combustible properties of the OGNEZA-M-KOR (NG) seal and the «OGNEBAZALT»PMBOR fire retardant material, declared by the manufacturers as non-combustible, are confirmed material.

Analysis of the curves in Figures 2-6 allows us to draw the following conclusions.

After heating the OGNEZA-LTU sealant sample (Figure 2) from 271 to $351{ }^{\circ} \mathrm{C}$ at $11-16$ minutes of testing, an increase and decrease in the sample mass are observed in a chaotic manner, which can be explained by the process of swelling and burnout of the organic components of the sealant composition in the resulting loose material structure. The maximum rate of sample weight loss $-20.5 \% /$ min occurs when the temperature reaches $355^{\circ} \mathrm{C}$ after 16 minutes of fire exposure. At a temperature of $360{ }^{\circ} \mathrm{C}$, the sample is likely to swell with an increase in its mass at a rate of $11.9 \% / \mathrm{min}$. At 21 -minutes of fire exposure at a temperature of $439{ }^{\circ} \mathrm{C}$, the organic component of the sample burns out at a rate of 9.0 $\% / \mathrm{min}$ and then swells at a temperature of $460{ }^{\circ} \mathrm{C}$. Subsequent changes in the rate of weight 
loss fluctuate in the range of $1.8-4.7 \% / \mathrm{min}$. Thus, by the 14 -th minute of testing and reaching $301{ }^{\circ} \mathrm{C}$, the OGNEZA-LTU sealant will perform protective functions. The swelling of the sample in conjunction with a smooth decrease in mass can be attributed to the advantage of the material (there is no instantaneous destruction of the material, respectively, the decrease in protective functions from hazardous fire factors is gradual).

After heating the OGNEZA-M-KOR (NG) seal sample (Figure 3), the mass loss rate varies from a minimum $-0.2 \% / \mathrm{min}$ at $49{ }^{\circ} \mathrm{C}$ to a maximum $-1.7 \% / \mathrm{min}$ at $349{ }^{\circ} \mathrm{C}(16$ minutes of testing). However, the decrease in mass observed at a given temperature is about $10 \%$ (mass.) And is probably associated with the decomposition and evaporation of the organic part of the sample and moisture. With a further increase in temperature, the rate of decrease in mass decreases, and at $564{ }^{\circ} \mathrm{C}$, it reaches zero. Thus, under high-temperature exposure, the studied material does not exhibit properties characteristic of flammable and combustible materials. The study results of the sample's behaviour confirm the noncombustible properties of the OGNEZA-M-KOR (NG) sealant declared by the manufacturer.

Analyzing the DTG curve of the fire seal OGNEZA-M-KOR (Figure 4), the following conclusions can be drawn. Starting from 15 minutes of thermal testing, a noticeable decrease in the mass of the test sample is observed, which reaches a maximum by 19.5 minutes at $341{ }^{\circ} \mathrm{C}(6.1 \% / \mathrm{min})$. After reaching a temperature of $571{ }^{\circ} \mathrm{C}$ at the 29 -th minute of research, the OGNEZA-M-KOR sample does not lose weight, demonstrating noncombustible properties.

The DTG curve of the fire-retardant material «OGNEBASALT» PMBOR (Figure 5) indicates an insignificant loss of sample weight over time - from $1.2 \% / \mathrm{min}$ at $337{ }^{\circ} \mathrm{C}$ to $3.5 \% / \mathrm{min}$ at $388^{\circ} \mathrm{C}$. In the time interval $15.0-22.5$ minutes, the rate of change in the mass of the sample is insignificant. After 27 minutes of exposure to temperature, the sample does not change up to $1000{ }^{\circ} \mathrm{C}$. A sample of fire-retardant material «OGNEBASALT» PMBOR demonstrates non-combustible properties.

In fig. 6 , the maximum rate of weight change $-11.9 \% / \mathrm{min}$ of the fire-retardant material OGNEZA-GT was observed at the 17 -th minute of testing at a temperature of $367{ }^{\circ} \mathrm{C}$. The duration of the process of changing the mass at a high rate is about 9 minutes and is probably related to the burnout of the organic part of the sample. A further increase in temperature is not associated with a noticeable decrease in the mass of the material.

The weight loss of test specimens of fire retardant materials upon heating (TG) is shown in Table 1.

Table 1. Characteristic of reducing the mass of samples of fire-retardant materials under thermal exposure

\begin{tabular}{|c|c|c|c|c|c|c|c|c|c|c|}
\hline & \multicolumn{10}{|c|}{ Weight loss of samples, $\%$ (upon reaching temperature, ${ }^{\circ} \mathrm{C}$ ) } \\
\hline & 10 & 20 & 30 & 40 & 50 & 60 & 70 & 80 & 90 & 100 \\
\hline \multirow{2}{*}{$\begin{array}{l}\text { OGNEZA } \\
\text {-LTU }\end{array}$} & 301 & 352 & 449 & 552 & 631 & 842 & 889 & 935 & Not achieved & \\
\hline & \multicolumn{10}{|c|}{ The overall weight reduction of the sample is $82 \%$. } \\
\hline \multirow{2}{*}{$\begin{array}{c}\text { OGNEZA } \\
\text {-M-KOR } \\
\text { (NG) }\end{array}$} & \multirow{2}{*}{\multicolumn{10}{|c|}{ No change in mass occurs when heated to a temperature of $1000^{\circ} \mathrm{C}$}} \\
\hline & & & & & & & & & & \\
\hline \multirow[t]{2}{*}{$\begin{array}{l}\text { OGNEZA } \\
\text {-M-KOR }\end{array}$} & 320 & 356 & 442 & \multicolumn{7}{|c|}{$\begin{array}{l}\text { Starting from a temperature of } 555^{\circ} \mathrm{C} \text {, there is no change in } \\
\text { mass. }\end{array}$} \\
\hline & \multicolumn{10}{|c|}{ The overall reduction in sample weight is $37 \%$. } \\
\hline \multirow{2}{*}{$\begin{array}{l}\text { «OGNEB } \\
\text { ASALT» } \\
\text { PMBOR }\end{array}$} & 395 & 481 & Sta & g fror & a temp & ture & $559^{\circ}$ & no c & ge in mass & \\
\hline & \multicolumn{10}{|c|}{ The overall reduction in sample weight is $21 \%$. } \\
\hline \multirow{2}{*}{$\begin{array}{l}\text { OGNEZA } \\
\text {-GT }\end{array}$} & 262 & 338 & 364 & 382 & 516 & 888 & No $n$ & ss los & ccurs. & \\
\hline & \multicolumn{10}{|c|}{ tion in sample weight is $64 \%$. } \\
\hline
\end{tabular}


Based on the data in Table 1, it can be concluded that for the loss of, for example, $10 \%$ of the mass, the test samples require different temperatures - from $262{ }^{\circ} \mathrm{C}$ to $461{ }^{\circ} \mathrm{C}$. OGNEZA-M-KOR (NG) shows the highest resistance to temperature with a total weight loss of only $11 \%$. «OGNEBASALT»PMBOR, OGNEZA-M-KOR, demonstrates high resistance to temperature.

The least resistant to the temperature of OGNEZA-LTU, in which almost complete combustion of the sample occurred: the weight reduction was $82 \%$. The change in the rate of weight reduction is reflected in the DTG curve of the sample, which recorded a large number of peaks in the temperature range from 271 to $460{ }^{\circ} \mathrm{C}$. The experiment has established the swelling of the OGNEZA-LTU sealing tape, which can cause weight loss. The sample exhibits fire-retardant properties, expanding many times when heated in volume and thereby preventing the propagation of combustion.

OGNEZA-GT sealant is a two-layer material consisting of dense and fibrous parts. After exposure to temperatures up to $1000{ }^{\circ} \mathrm{C}$, the fibrous structure of the material is preserved, ensuring the integrity of $36 \%$ of the sealant structure. The fire-retardant properties of this sample are probably associated not with the resistance to ignition but with the expansion of the non-combustible part in the volume, similar to the OGNEZA-LTU sealing tape.

\section{Conclusions}

1. The rates of weight loss of the investigated fire-retardant materials have been studied. A high rate of weight loss was established for OGNEZA-LTU samples $(20.5 \% / \mathrm{min}$ at 335 $\left.{ }^{\circ} \mathrm{C}\right)$ and OGNEZA-GT $\left(11.9 \% / \mathrm{min}\right.$ at $\left.369^{\circ} \mathrm{C}\right)$. A low rate of weight loss was noted in the samples OGNEZA-M-KOR (NG) - $1.7 \% / \mathrm{min}$ at $349{ }^{\circ} \mathrm{C}$, OGNEZA-M-KOR -6.1 $\% / \mathrm{min}$ at $341{ }^{\circ} \mathrm{C}$, «OGNEZALT»PMBOR $-3,5 \% / \mathrm{min}$ at $388^{\circ} \mathrm{C}$. Time intervals of weight loss have been determined: all tested samples have maximum weight loss in the range of 15-20 minutes.

2. The temperature ranges of the maximum rate of weight loss have been determined: 349 $-388^{\circ} \mathrm{C}$.

3. The best heat-resistant properties were shown by OGNEZA-M-KOR (NG), «OGNEBA-ZALT» PMBOR, OGNEZA-M-KOR.

The research results can be used to substantiate the choice of fire protection in buildings of various functional classes of fire hazard.

\section{References}

1. Arunjothi R., Kumar P., Meena K. Heat and Fire Properties of Low Smoke Zero Halogen Materials of Power Cables, (2020)

2. Manich A., Pérez-Rentero S., Alonso C., Coderch L., Martí M. Thermal Analysis of Healthy and Ecological Friendly Flame Retardants for Textiles, KnE Engineering, (2020), 10.18502/keg.v5i6.7028.

3. Sauerbier P., Mayer A., Emmerich L., Militz H. Fire Retardant Treatment of Wood State of the Art and Future Perspectives, (2020), 10.1007/978-3-030-41235-7_14.

4. Shahari Sh., Fathullah M., Abdullah M. Recent developments in fire retardant glass fibre reinforced epoxy composite and geopolymer as a potential fire-retardant material, Construction and Building Materials, 277. (2021)

5. Albright, John Taylor, David. Heat resistant and fire retardant materials and methods for preparing same. (2013), Patent:US8492471B2

6. Alam Maksudul., Biswas Bidyut., Nedeltchev, Alexi Han., Haesook Ranasinghe., Asanga Bhowmik., Pradip Goswami, Kisholoy. Phosphine Oxide Containing 
Poly(pyridinium salt)s as Fire Retardant Materials. Polymers (2019), 11, p.1141, doi:10.3390/polym11071141.

7. Rawal Shannay and Manickam Ramachandran. Effect of fire retardancy materials in fibre reinforced composite plate for false ceilings, Materials Science and Engineering, 810, (2020), doi:10.1088/1757-899X/810/1/012023.

8. Bogdanova Valentina, Kobets Olga, Vrublevsky Alexander. Dependence of the fire retardant and fire extinguishing efficiency of compositions based on phosphates of bivalent and trivalent ammonium metals on their physicochemical properties. Journal of Civil Protection. 4, pp. 367-377, (2020)

9. Handa Takashi, Takahashi Atsushi, Nagashima Toshiaki, Gotoda Masao, Ebihara Naofumi, Saito Minoru, Ikeda Yasuhisa. Combustion characteristics and the smoking behavior of fire-retarded materials - 1. Small furnace test for the analysis on the combustion characteristics and the smoking behavior of the fire-retarded polymer materials, (2021)

10. Medved Sergej, Jones Dennis, Faelled Paw, Pirš Dejan, Humar Miha, Lesar Boštjan, Investigation of Fire-Retardant Additive on Particleboard Properties, International Panel Products Symposium, (2020)

11. Zheng Chao Li, Dongfang Ek Monica. Improving fire retardancy of cellulosic thermal insulating materials by coating with bio-based fire retardants. Nordic Pulp and Paper Research Journal, (2019), 34. 96-106. 10.1515/npprj-2018-0031.

12. Rybakov V., Jos V., Raimova I., and Kudryavtsev K. Modal analysis of frameless arches made of thin-walled steel profiles. IOP Conf. Ser. Mater. Sci. Eng. 883, (2020)

13. Zheng Chao Li, Dongfang Ek Monica. Improving fire retardancy of cellulosic thermal insulating materials by coating with bio-based fire retardants. Nordic Pulp and Paper Research Journal, (2019), 34. 96-106. 10.1515/npprj-2018-0031.

14. Kattakulov F., Muslimov T., Khusainov A., Vokhidov O., Sultanov, S. Water resource saving in irrigation networks through improving the efficiency of reinforced concrete coatings, IOP Conference Series: Materials Science and Engineering, 883(1), 2020

15. Eremina Tatiana, Korolchenko Dmitry. Fire Protection of Building Constructions with the Use of Fire-Retardant Intumescent Compositions. Buildings, (2020)

16. Pestereva L., Shakirov N. Shakirova Olga. Intumescent Type Fire Retardant Epoxy Coating. Materials Science Forum. 992. pp. 605-609. (2020), 10.4028/www.scientific.net/MSF.992.605.

17. Golovanov Vladimir., Pekhotikov Andrey., Pavlov Vladimir. Evaluation of fireretardant effectiveness of coatings for steel structures. pp. 43-54, (2020) 10.37657/vniipo.pb.2020.101.4.004. DOI: 10.37657 / vniipo.pb.2020.101.4.004

18. Zhang Feng, Wang Yong, Jin Yang, Zhang Jun. Experimental Study on Thermal Diffusivity of Intumescent Fire-Retardant Materials. Advanced Materials Research. pp. 550-553. (2012) 